\title{
Avaliação da função alimentar em crianças com microcefalia por Zika Vírus: acompanhamento de dois anos
}

\author{
Evaluation of food function in children microcephaly by Zilka Virus: two-year follow-up \\ Evaluación de la función alimentaria en niños con microcefalia por Virus Zika: seguimiento a dos \\ años
}

\section{Resumo}

As sequelas da microcefalia são variáveis de acordo com a gravidade da lesão, no entanto, poucos são os relatos da função alimentar em crianças com microcefalia por Zika vírus. Objetivo: avaliar a função alimentar em crianças microcefalia por Zika vírus. Foram avaliadas 43 crianças com diagnóstico de microcefalia por SCZ, divididas em três grupos, de acordo com a faixa etária das crianças compreendida da seguinte maneira: Faixa Etária 1(FE1) com idade entre 0 a 6 meses; Faixa Etária 2(FE2) com idade entre 6 meses e 1 dia a 36 meses; Faixa Etária 3(FE3) com idade entre 36 meses e 1 dia a 48 meses. Foram analisados aspectos específicos da alimentação e comportamento alimentar da criança, além de avaliação fonoaudiológica. As avaliações foram definidas pelo protocolo criado pelo serviço clínico, frente à ausência de protocolos validados para a amostra estudada. Para a análise, os resultados foram apresentados em distribuição percentual simples e absoluta. Os sinais sugestivos de aspiração estiveram com maior frequência na FE2, enquanto que nas FE1 e 3 houve menor incidência de crianças com este sinal de comprometimento na deglutição. $\mathrm{N}$ avaliação da deglutição com alimento pastoso foi observada durante a captação do alimento, oclusão labial alterada nas FE2 e 3. em 45,5\% das crianças da faixa etária 2 e 45,8\% da faixa etária 3. Presença de escape extraoral, tempo de trânsito oral, tosse, resíduos pós-deglutição, elevação laríngea e com menor incidência, os sinais sugestivos de aspiração nas FE2 e 3. Foi possível concluir que ocorreram importantes alterações nas funções de sucção e deglutição. Estes achados indicam que esta população deve ser mantida em acompanhamento multidisciplinar.

Palavras-chave: Zika Vírus; Microcefalia; Deglutição; Transtornos de deglutição; Desenvolvimento infantil.

\begin{abstract}
The sequelae of microcephaly vary according to the severity of the lesion, however, there are few reports of food function in children with microcephaly caused by Zika virus. Objective: to evaluate the food function in children with Zika virus microcephaly. Forty-three children diagnosed with SCZ microcephaly were evaluated, divided into three groups, according to the age range of the children, understood as follows: Age Range 1 (FE1) aged between 0 and 6 months; Age group 2(FE2) aged between 6 months and 1 day to 36 months; Age group 3(FE3) aged between 36 months and 1 day to 48 months. Specific aspects of the child's feeding and eating behavior were analyzed, as well as speech therapy assessment. The evaluations were defined by the protocol created by the clinical service, given the absence of validated protocols for the studied sample. For the analysis, the results were presented in simple and
\end{abstract}


absolute percentage distribution. Signs suggestive of aspiration were more frequent in FE2, while in FE1 and 3 there was a lower incidence of children with this sign of impairment in swallowing. In the evaluation of swallowing with pasty food was observed during food uptake, altered lip occlusion in FE2 and 3. in $45.5 \%$ of children in age group 2 and $45.8 \%$ in age group 3. Presence of extraoral escape, time of oral transit, coughing, post-swallowing residues, laryngeal elevation and, with a lower incidence, the suggestive signs of aspiration in FE2 and 3. It was possible to conclude that there were important alterations in the functions of sucking and swallowing. These findings indicate that this population should be kept under multidisciplinary follow-up.

Keywords: Zika Virus; Microcephaly; Deglutition; Deglutition disorders; Child development.

\section{Resumen}

Como sequelas da microcefalia são variáveis de acordo com a gravidade da lesão, no entanto, poucos são os relatos da função alimentar em crianças com microcefalia por Zika vírus. Objetivo: avaliar una função alimentar em crianças microcefalia por Zika vírus. Foram avaliadas 43 crianças con diagnóstico de microcefalia por SCZ, divididas em três grupos, de acordo con faixa etária das crianças compreendida da seguinte maneira: Faixa Etária 1 (FE1) com idade entre 0 a 6 meses; Faixa Etária 2 (FE2) com idade entre 6 meses y 1 día a 36 meses; Faixa Etária 3 (FE3) com idade entre 36 meses y 1 día a 48 meses. Foram analisados aspectos específicos de la alimentación y el comportamiento alimentar da criança, além de avaliação fonoaudiológica. Como avaliações foram definidas pelo protocolo criado pelo serviço clínico, frente à ausência de protocolos validados para amostra estudada. Para un análisis, os resultados de apresentados em distribuição percentual simples e absoluta. Os sinais sugestivos de aspiração estiveram com maior frequência na FE2, enquanto que nas FE1 e 3 houve menor incidência de crianças com este sinal de comprometimento na deglutição. $\mathrm{N}$ avaliação da deglutição com alimento pastoso foi observada durante a captação do alimento, oclusão labial alterada nas FE2 e 3. em 45,5\% das crianças da faixa etária 2 e 45,8\% da faixa etária 3. Presença de escape extraoral, tempo de tránsito oral, tosse, resíduos pós-deglutição, elevação laríngea e com menor incidência, os sinais sugestivos de aspiração nas FE2 e 3. Foi possível concluir que ocorreram importantes alteraciones nas funções de sucção e deglutição. Estes achados indicam que esta população deve ser mantida em acompanhamento multidisciplinar.

Palabras clave: Virus Zika.; Microcefalia; Deglución; Trastornos de la deglución; Desarrollo infantil.

\section{Introdução}

A Síndrome Congênita pelo Zika vírus (SCZ) é um conjunto de sinais cerebrais encontrados nas crianças infectadas pelo ZIKV, são elas: calcificação intracraniana, ventriculometria e volume cerebral diminuído, que pode apresentar microcefalia ao nascer ou posteriormente (Teixeira et al., 2020). Estudos sugerem que a infecção pelo ZIKV promove manifestações clínicas e graves comprometimentos neurológicos, como a Síndrome de Guillain-Barré e meningoencefalites (Carteaux et al., 2016; Oehler et al., 2014; Reis, 2015), além de infecções em gestantes, com possíveis anomalias ao feto, incluindo a microcefalia (Brasil et al., 2016; Krauer et al., 2017; Mlakar et al., 2016).

A microcefalia é uma malformação congênita, na qual o cérebro do recém-nascido não se desenvolve de maneira adequada (WHO, 2016) e seu perímetro cefálico (PC) é menor que dois ou mais desvios-padrão (DP) que a média para a idade e sexo. Quando esta condição atinge a medida menor que menos três DP é caracterizada como microcefalia grave (Opitz \& Holt, 1990). A microcefalia causa atraso no desenvolvimento global da criança, como, atraso cognitivo e na fala, transtorno do espectro autista, perda auditiva neurossensorial e disfagia, consideradas graves alterações fonoaudiológicas (Ashwal et al., 2009; Gazeta et al., 2021).

A literatura tem demonstrado que a microcefalia por ZIKV traz prejuízos orais importantes à criança como alterações do tônus muscular (hipotonia ou hipertonia), linguagem prejudicada, retrognatia, desproporção craniofacial, frênulo da língua alterado, ausência de reflexos estapedianos, alterações auditivas e disfagia (Rosa et al., 2020). (Marques et al., 2018) analisaram as funções orais em crianças com microcefalia e concluíram que as funções mais afetadas foram deglutição, respiração, tonicidade muscular e erupção dentária. Marinho (2019) encontrou alterações no sistema estomatognático em crianças com SCZ, com destaque para as dificuldades na deglutição encontrou alterações no sistema estomatognático em crianças com SCZ, com destaque para as dificuldades na deglutição. (Almeida et al., 2019) demonstrou através da avaliação clínica, presença de alteração nas fases oral e/ou faríngea da deglutição em $42 \%$ de crianças de 0 a 3 anos de idade com 
microcefalia. Por outro lado, ainda não está completamente elucidado na literatura sobre o acompanhamento da função alimentar das crianças com microcefalia decorrentes do ZIKV.

Assim, as consequências diretas dessa doença na alimentação e nas funções de deglutição e suç̧ão ainda são pouco exploradas e estudadas nessa população. Diante do exposto o objetivo do presente estudo foi avaliar a função alimentar em crianças microcefalia por Zika vírus.

\section{Metodologia}

O presente estudo foi descritivo, quantitativo, do tipo estudo de caso, segundo as recomendações de Pereira et al. (2018). Os procedimentos de pesquisa seguiram as recomendações para critérios e requisitos estabelecidos pela resolução 466/2012.2. 2 e foi aprovado pelo Comitê de Ética e Pesquisa sob o protocolo 0373.107.000-15.

Participaram do estudo 43 crianças com diagnóstico de microcefalia por SCZ, divididas em três grupos, de acordo com a faixa etária das crianças compreendida da seguinte maneira: Faixa Etária 1(FE1) - composta por 43 crianças com idade entre 0 a 6 meses; Faixa Etária 2(FE2) - composta por 22 crianças, com idade entre 6 meses e 1 dia a 36 meses; Faixa Etária 3(FE3) - constituída por 24 crianças, com idade entre 36 meses e 1 dia a 48 meses.

O diagnóstico de SCZ foi realizado de acordo com os seguintes critérios: achado ultrassonográfico fetal com aferição da circunferência craniana menor que dois desvios padrão $(<2 \mathrm{DP})$ abaixo da média para a idade gestacional com a presença ou não de outras alterações do SNC, e excluídas outras possíveis causas infecciosas e não infecciosas ou com diagnóstico laboratorial conclusivo para Zika vírus; Achado ultrassonográfico fetal com alteração do SNC sugestivo de infecção congênita, com relato de exantema na mãe durante a gravidez, e excluídas outras possíveis causas infecciosas e não infecciosas ou com diagnóstico laboratorial conclusivo para o Zika vírus (Ministério da Saúde, 2015).

Foram incluídos no estudo os prontuários que continham: diagnóstico de microcefalia por Zika vírus de acordo com os critérios (Ministério da Saúde, 2015) laboratoriais e/ou exames complementares; prontuários completos dentro dos parâmetros utilizados na Instituição. Como critérios de exclusão: crianças com presença de comorbidades que mascarassem as características da SCZ, como Síndrome de Down, presença comprovada de TORSCH (Toxoplasmose, Rubéola, Citomegalovirus e Vírus Herpes simples) durante a gestação.

\section{Procedimentos de coleta}

Foram coletadas e tabuladas todas as informações referentes ao desenvolvimento motor oral das crianças e as funções de sucção e deglutição descritas nos roteiros de anamnese e de avaliação do Ambulatório de Fonoaudiologia no período de janeiro de 2015 a fevereiro de 2020. Os dados registrados foram realizados por duas fonoaudiólogas, especialistas e com experiência na área de Motricidade Oral e Disfagia, responsáveis pelo serviço.

Foi realizada anamnese, através de respostas do cuidador/mãe, com os dados de identificação, do nascimento e alimentação da criança como: data de nascimento e sexo; período gestacional, perímetro cefálico, Apgar, peso e altura; resultados da avaliação neurológica, realizada por um neuropediatra. A última parte da anamnese continha os dados específicos da alimentação e comportamento alimentar da criança, tais como: queixas, alteração na deglutição, utensílios para alimentação, introdução de alimentos de diferentes consistências, sinais de disfagia, dificuldade alimentar, uso de vias de alimentação alternativa, atitudes facilitadoras da deglutição, ocorrências de crises convulsivas e refluxo gastresofágico. 


\section{Avaliação Fonoaudiológica}

Para avaliação fonoaudiológica foi utilizado o Roteiro de Avaliação Fonoaudiológica adaptado de Fujinaga, et al. (2008) utilizada no Serviço de Fonoaudiologia. Este roteiro de avaliação relaciona idade gestacional/prematuridade e prontidão para início da alimentação oral, a partir de dados do estado de alerta, postura e tonicidade de lábios, língua e bochechas, palato duro e reflexos orais. Para a avaliação dos aspectos da deglutição foi utilizado o protocolo proposto por Vianna \& Suzuki (2011). A escolha destes instrumentos foi devido ao fato da inexistência de protocolos validados e traduzidos, naquele período, para a população deste estudo.

A avaliação da deglutição (Vianna \& Suzuki, 2011) incluiu informações referentes à forma de alimentação da criança que englobaram dados da amamentação, da introdução de mamadeira e outros utensílios (colher, copo) e das consistências alimentares líquida, pastosa e sólida, bem como a presença de regurgitação nasal, escape oral, refluxo gastroesofágico, engas go e/ou tosse, durante ou após a oferta alimentar. Também foram coletados dados sobre a via alimentar: oral, nasoenteral, gastrostomia ou mista. Na avaliação funcional da deglutição a criança foi acomodada no colo da mãe ou responsável, de modo a inibir os padrões reflexos alterados, e possibilitou os movimentos isolados dos braços, cabeça, mandíbula, língua e lábios. A deglutição foi avaliada por meio de alimentos fornecidos pelos cuidadores na consistência que geralmente é consumida pela criança na sua rotina alimentar e oferecido através de utensílios, como mamadeira e colheres da criança.

Foram ofertadas as consistências líquida (água ou leite) e/ou pastosa (leite engrossado, sopa liquidificada ou iogurte) e observados aspectos de posturas de lábios, língua e mandíbula na captação do alimento e no momento da deglutição. Foi considerada adequada à condição de vedamento labial, a ampla abertura de mandíbula, com movimentos suaves e ritmados de abertura, a protrusão e a retração e língua apoiada no assoalho da boca com a ponta arredondada.

No momento da deglutição, para ambas as consistências testadas foram consideradas alteradas: os sinais de regurgitação nasal; escape oral (definido como a queda do alimento para fora da boca); tempo de trânsito oral aumentado (quando o bolo alimentar permanece mais que seis segundos na cavidade oral); tosse; sinais sugestivos de aspiração, tais como, engasgos durante e após a deglutição, cansaço após a deglutição, cianose e tosse; ejeção adequada; resíduos após a deglutição (presença de restos alimentares no vestíbulo anterior, lateral, assoalho da boca e/ou superfície da língua) e elevação laríngea.

Para apresentação dos dados da presente pesquisa foi realizada uma análise descritiva e qualitativa, através de distribuição percentual simples.

\section{Resultados}

A amostra foi composta por 43 crianças diagnosticadas com microcefalia associada ao ZIKV, sendo, 22 crianças do sexo masculino e 21 do feminino. O perímetro cefálico apresentou como menor perímetro $22,5 \mathrm{~cm}$ e maior $32 \mathrm{~cm}$, com mediana de $29,5 \mathrm{~cm}$. Na avaliação da organização comportamental foi observada predominância da condição de alerta em relação a sono leve e profundo em todas as faixas etárias (Tabela 1). O estado de alerta, postura e tônus global das crianças com microcefalia associada ao ZIKV estão descritas na Tabela 1. 
Tabela 1. Distribuição dos resultados das avaliações da organização comportamental segundo o estado de alerta, postura global e tônus global de crianças com microcefalia associada ao ZIKV no período de 2015 a 2020.

\begin{tabular}{|c|c|c|c|c|}
\hline & & $\begin{array}{c}\text { FE1 (43) } \\
\text { n } / \%\end{array}$ & $\begin{array}{r}\text { FE2 (22) } \\
\text { n/\% }\end{array}$ & $\begin{array}{c}\text { FE3 (24) } \\
\text { n/\% }\end{array}$ \\
\hline \multirow{4}{*}{ Estado de Alerta } & $\mathrm{A}$ & $12(27,9)$ & $20(91,0)$ & $24(100,0)$ \\
\hline & SL & $2(4,7)$ & $1(4,5)$ & $0(0,0)$ \\
\hline & SP & $3(6,9)$ & $1(4,5)$ & $0(0,0)$ \\
\hline & NR & $26(60,5)$ & $0(0,0)$ & $0(0,0)$ \\
\hline \multirow{4}{*}{ Postura Global } & $\mathrm{F}$ & $4(9,3)$ & $5(22,7)$ & $7(29,1)$ \\
\hline & SF & $3(7,0)$ & $9(40,9)$ & $11(45,9)$ \\
\hline & EXT & $24(55,8)$ & $8(36,4)$ & $6(25,0)$ \\
\hline & NR & $12(27,9)$ & $0(0,0)$ & $0(0,0)$ \\
\hline \multirow{4}{*}{ Tônus Global } & $\mathrm{N}$ & $2(4,7)$ & $1(4,6)$ & $1(4,2)$ \\
\hline & HIPO & $2(4,7)$ & $5(22,7)$ & $6(25,0)$ \\
\hline & HIPER & $33(76,7)$ & $16(72,7)$ & $17(70,8)$ \\
\hline & NR & $6(13,9)$ & $0(0,0)$ & $0(0,0)$ \\
\hline
\end{tabular}

Legenda: FE1 = faixa etária 1; FE2 = faixa etária 2; FE3 = faixa etária 3

$\mathrm{A}=$ Alerta; $\mathrm{SL}=$ sono leve; $\mathrm{SP}=$ sono profundo; $\mathrm{NR}=$ não respondeu; $\mathrm{F}=$ flexão; $\mathrm{SF}=$ semiflexão; $\mathrm{Ext}=$ extensão; $\mathrm{N}=$ normal; Hipo= hipotonia; Hiper= hipertonia. Fonte: Própria pesquisa.

Durante o período de amamentação foram observados sinais importantes de disfagia, como engasgo, escape extraoral e tosse. A via de alimentação nutricional de todas as crianças da FE1 foi exclusivamente oral. A partir da FE2, uma (4,5\%) criança passou a alimentarem-se por via alternativa de alimentação (gastrostomia), e na FE3, cinco (20,8\%) crianças utilizaram, exclusivamente, essa via alimentar e, duas delas passaram a alimentar-se de modo misto, tanto na FE2 (9,1\%) como na FE3 $(8,3 \%)$, ou seja, por duas vias alimentares, oral e gastrostomia. 
Tabela 2. Distribuição em valores absolutos (n) e relativos (\%) dos resultados das avaliações segundo a alimentação uso de mamadeira e deglutição de alimentos pastoso e líquido de crianças com microcefalia associada ao Zika vírus nas faixas etária 1,2 e 3 , atendidas no período de 2015 a 2020.

\begin{tabular}{|c|c|c|c|c|c|c|c|c|c|c|c|}
\hline & \multicolumn{4}{|c|}{ AMAMENTAÇÃO } & \multicolumn{3}{|c|}{ MAMADEIRA } & \multicolumn{2}{|c|}{ PASTOSO } & \multicolumn{2}{|c|}{ LÍQUIDO } \\
\hline & & $\begin{array}{c}\operatorname{FE1}(43) \\
(n / \%)\end{array}$ & $\begin{array}{c}\text { FE2(15) } \\
(\mathbf{n} / \%)\end{array}$ & $\begin{array}{r}\text { FE3(6) } \\
(n / \%)\end{array}$ & $\begin{array}{c}\text { FE1(43) } \\
(n / \%)\end{array}$ & $\begin{array}{r}\text { FE2(18) } \\
(\mathbf{n} / \%)\end{array}$ & $\begin{array}{c}\text { FE3(11) } \\
(\mathbf{n} / \%)\end{array}$ & $\begin{array}{c}\text { FE2(22) } \\
(\mathbf{n} / \%)\end{array}$ & $\begin{array}{c}\text { FE3(19) } \\
(\mathbf{n} / \%)\end{array}$ & $\begin{array}{r}\text { FE2(18) } \\
(\mathbf{n} / \%)\end{array}$ & $\begin{array}{r}\text { FE3(15) } \\
(\mathbf{n} / \%)\end{array}$ \\
\hline \multirow{3}{*}{ Tipo } & Adeq & $29(67,4)$ & $12(80,0)$ & $6(100,0)$ & $25(58,1)$ & $18(100,0)$ & $11(100,0)$ & - & - & - & - \\
\hline & Alt & $10(23,3)$ & $3(20,0)$ & $0(0,0)$ & $4(9,3)$ & $0(0,0)$ & $0(0,0)$ & - & - & - & - \\
\hline & NR & $4(9,3)$ & - & - & $14(32,6)$ & - & - & - & - & - & - \\
\hline \multirow{3}{*}{$\begin{array}{c}\text { Regurgitação } \\
\text { Nasal }\end{array}$} & Adeq & $37(86,0)$ & $13(86,7)$ & $6(100,0)$ & $28(65,1)$ & $14(77,8)$ & $11(100,0)$ & $18(81,8)$ & $19(100,0)$ & $16(88,9)$ & $14(93,3)$ \\
\hline & Alt & $2(4,7)$ & $2(13,3)$ & $0(0,0)$ & $1(2,3)$ & $4(22,2)$ & $0(0,0)$ & $4(18,2)$ & $0(0,0)$ & $2(11,1)$ & $1(6,7)$ \\
\hline & NR & $4(9,3)$ & - & - & $14(32,6)$ & - & - & - & - & - & - \\
\hline \multirow{4}{*}{$\begin{array}{c}\text { Escape } \\
\text { Extraoral }\end{array}$} & Adeq & $28(65,1)$ & $10(66,7)$ & $6(100,0)$ & $13(30,2)$ & $5(27,8)$ & $3(27,3)$ & $7(31,8)$ & $10(52,6)$ & $7(38,9)$ & $8(53,3)$ \\
\hline & Alt & $11(25,6)$ & $5(33,3)$ & $0(0,0)$ & $16(37,2)$ & $13(72,2)$ & $8(72,7)$ & $15(68,2)$ & $9(47,4)$ & $11(61,1)$ & $7(46,7)$ \\
\hline & NR & $4(9,3)$ & - & - & $14(32,6)$ & - & - & - & - & - & - \\
\hline & Adeq & $28(65,1)$ & $10(66,7)$ & $4(66,7)$ & $19(44,2)$ & $12(66,7)$ & $8(72,7)$ & $14(63,6)$ & $11(57,9)$ & $11(61,1)$ & $13(86,7)$ \\
\hline \multirow[t]{2}{*}{$\begin{array}{c}\text { Refluxo } \\
\text { Gastriesofágico }\end{array}$} & Alt & $11(25,6)$ & $5(33,3)$ & $2(33,3)$ & $10(23,2)$ & $6(33,3)$ & $3(27,3)$ & $8(36,4)$ & $8(42,1)$ & $7(38,9)$ & $2(13,3)$ \\
\hline & NR & $4(9,3)$ & - & - & $14(32,6)$ & - & - & - & - & - & - \\
\hline \multirow[t]{4}{*}{ Engasgo } & Adeq & $20(46,5)$ & $10(66,7)$ & $6(100,0)$ & $18(41,9)$ & $10(55,6)$ & $9(81,8)$ & $12(54,5)$ & $11(57,9)$ & $8(44,4)$ & $6(40,0)$ \\
\hline & Alt & $19(44,2)$ & $5(33,3)$ & $0(0,0)$ & $11(25,5)$ & $8(44,4)$ & $2(18,2)$ & $10(45,5)$ & $8(42,1)$ & $10(55,6)$ & $9(60,0)$ \\
\hline & NR & $4(9,3)$ & - & - & $14(32,6)$ & - & - & - & - & - & - \\
\hline & Adeq & $34(79,1)$ & $9(60,0)$ & $6(100,0)$ & $26(60,5)$ & $11(61,1)$ & $9(81,8)$ & $11(50,0)$ & $8(42,1)$ & $8(44,4)$ & $8(53,3)$ \\
\hline Tosse & Alt & $5(11,6)$ & $6(40,0)$ & $0(0,0)$ & $3(6,9)$ & $7(38,9)$ & $2(18,2)$ & $11(50,0)$ & $11(57,9)$ & $10(55,6)$ & $7(46,7)$ \\
\hline \multirow{4}{*}{$\begin{array}{l}\text { Resíduos Pós } \\
\text { Deglutição }\end{array}$} & NR & $4(9,3)$ & - & - & $14(32,6)$ & - & - & - & - & - & - \\
\hline & Adeq & - & - & - & - & - & - & $4(18,2)$ & $2(10,5)$ & $8(44,4)$ & $5(33,3)$ \\
\hline & Alt & - & - & - & - & - & - & $14(63,6)$ & $17(89,5)$ & $9(50,0)$ & $10(66,7)$ \\
\hline & NR & - & - & - & - & - & - & $4(18,2)$ & - & $1(5,6)$ & - \\
\hline
\end{tabular}

Legenda: FE1= faixa etária 1; FE2= faixa etária 2; FE3= faixa etária 3; ADEQ= adequado; ALT= alterado; NR= não respondeu Fonte: Própria pesquisa

Para a avaliação funcional da deglutição com alimento pastoso foi observada, durante a captação do alimento, oclusão labial alterada nas FE2 e 3. em $10(45,5 \%)$ crianças da faixa etária 2 e $11(45,8 \%)$ da faixa etária 3 . A abertura de mandíbula mostrou-se alterada principalmente na FE3. em duas $(9,0 \%)$ crianças da faixa etária 2 e sete $(29,2 \%)$ da faixa etária 3. O posicionamento de língua protruída, apresentou em três $(13,6 \%)$ crianças da faixa etária 2 e em cinco $(20,8 \%)$ da faixa etária 3.

$\mathrm{Na}$ avaliação durante a deglutição do alimento pastoso, a oclusão labial e, em menor proporção, a protrusão de língua, estiveram alteradas nas FE2 e 3. Houve a ocorrência de escape extraoral, tempo de trânsito oral, tosse, resíduos pós-deglutição, elevação laríngea e com menor incidência, os sinais sugestivos de aspiração nas FE2 e 3. A Tabela 3 apresenta respostas alteradas na oclusão labial e no posicionamento de língua nas três faixas etárias avaliadas durante a deglutição de líquidos. Outros aspectos como: escapes extraorais, tempo de trânsito oral alterado e tosse, também foram observados nas três faixas etárias. Os sinais sugestivos de aspiração estiveram com maior frequência na FE2, enquanto que nas FE1 e 3 houve menor 
incidência de crianças com este sinal de comprometimento na deglutição. As avaliações da deglutição de alimentos pastosos e líquidos nas faixas etárias 1, 2 e 3 estão descritas na Tabela 3.

Tabela 3. Distribuição dos resultados em valores absolutos (n) e relativos (\%) da deglutição de alimentos pastoso e líquido das crianças com microcefalia associada ao Zika vírus no período de 2015 a 2020.

\begin{tabular}{|c|c|c|c|c|c|c|c|}
\hline & & \multicolumn{3}{|c|}{ DEGLUTIÇÃO LÍQUIDO } & \multicolumn{3}{|c|}{ DEGLUTIÇÃO PASTOSO } \\
\hline & & $\begin{array}{c}\text { FE1(43) } \\
(\mathbf{n} / \%)\end{array}$ & $\begin{array}{c}\text { FE2(22) } \\
(\mathbf{n} / \%)\end{array}$ & $\begin{array}{c}\text { FE3(24) } \\
(\mathbf{n} / \%)\end{array}$ & $\begin{array}{c}\text { FE1(43) } \\
(\mathbf{n} / \%)\end{array}$ & $\begin{array}{c}\text { FE2(22) } \\
(\mathbf{n} / \%)\end{array}$ & $\begin{array}{c}\text { FE3(24) } \\
(\mathbf{n} / \%)\end{array}$ \\
\hline \multirow{3}{*}{ Lábios Ocluídos } & Adeq & $28(65,1)$ & $1(4,5)$ & $0(0,0)$ & - & $2(9,0)$ & $2(8,3)$ \\
\hline & Alt & $6(14,0)$ & $15(68,2)$ & $15(62,5)$ & - & $10(45,5)$ & $13(54,2)$ \\
\hline & NR & $9(20,9)$ & $6(27,3)$ & $9(37,5)$ & - & $10(45,5)$ & $9(37,5)$ \\
\hline \multirow{3}{*}{ Língua Protruida } & Adeq & $23(53,5)$ & $13(59,1)$ & $12(50,0)$ & - & $7(31,8)$ & $11(45,8)$ \\
\hline & Alt & $12(27,9)$ & $3(13,6)$ & $3(12,5)$ & - & $5(22,7)$ & $4(16,7)$ \\
\hline & NR & $8(18,6)$ & $6(27,3)$ & $9(37,5)$ & - & $10(45,5)$ & $9(37,5)$ \\
\hline \multirow{3}{*}{ Regurgitação Nasal } & Adeq & $35(81,4)$ & $15(68,2)$ & $15(62,5)$ & - & $12(54,5)$ & $15(62,5)$ \\
\hline & Alt & $1(2,3)$ & $1(4,5)$ & $0(0,0)$ & - & $0(0,0)$ & $0(0,0)$ \\
\hline & NR & $7(16,3)$ & $6(27,3)$ & $9(37,5)$ & - & $10(45,5)$ & $9(37,5)$ \\
\hline \multirow{3}{*}{ Escape Extra Oral } & Adeq & $19(44,2)$ & $3(13,6)$ & $2(8,3)$ & - & $0(0,0)$ & $5(20,8)$ \\
\hline & Alt & $16(37,2)$ & $13(59,1)$ & $13(54,2)$ & - & $12(54,5)$ & $10(41,7)$ \\
\hline & NR & $8(18,6)$ & $6(27,3)$ & $9(37,5)$ & - & $10(45,5)$ & $9(37,5)$ \\
\hline \multirow{3}{*}{$\begin{array}{c}\text { Tempo de Trânsito } \\
\text { Oral }\end{array}$} & Adeq & $22(51,2)$ & $4(18,2)$ & $4(16,7)$ & - & $3(13,6)$ & $4(16,7)$ \\
\hline & Alt & $13(30,2)$ & $12(54,5)$ & $11(45,8)$ & - & $9(40,9)$ & $11(45,8)$ \\
\hline & NR & $8(18,6)$ & $6(27,3)$ & $9(37,5)$ & - & $10(45,5)$ & $9(37,5)$ \\
\hline \multirow{3}{*}{ Tosse } & Adeq & $31(72,1)$ & $7(31,8)$ & $10(41,7)$ & - & $9(40,9)$ & $12(50,0)$ \\
\hline & Alt & $4(9,3)$ & $9(40,9)$ & $5(20,8)$ & - & $3(13,6)$ & $3(12,5)$ \\
\hline & NR & $8(18,6)$ & $6(27,3)$ & $9(37,5)$ & - & $10(45,5)$ & $9(37,5)$ \\
\hline \multirow{3}{*}{$\begin{array}{l}\text { Sinais Sugestivos de } \\
\text { Aspiração }\end{array}$} & Adeq & $33(76,7)$ & $6(27,3)$ & $11(45,8)$ & - & $8(36,3)$ & $12(50,0)$ \\
\hline & Alt & $2(4,7)$ & $10(45,4)$ & $4(16,7)$ & - & $4(18,2)$ & $3(12,5)$ \\
\hline & NR & $8(18,6)$ & $6(27,3)$ & $9(37,5)$ & - & $10(45,5)$ & $9(37,5)$ \\
\hline \multirow{3}{*}{ Ejeção Adequada } & Adeq & $27(62,8)$ & $6(27,3)$ & $8(33,3)$ & - & $5(22,7)$ & $8(33,3)$ \\
\hline & Alt & $8(18,6)$ & $10(45,4)$ & $7(29,2)$ & - & $7(31,8)$ & $7(29,2)$ \\
\hline & NR & $8(18,6)$ & $6(27,3)$ & $9(37,5)$ & - & $10(45,5)$ & $9(37,5)$ \\
\hline \multirow{3}{*}{$\begin{array}{l}\text { Resíduos Após } \\
\text { Deglutição }\end{array}$} & Adeq & $26(60,5)$ & $7(31,8)$ & $9(37,5)$ & - & $2(9,0)$ & $3(12,5)$ \\
\hline & Alt & $8(18,6)$ & $9(40,9)$ & $6(25,0)$ & - & $10(45,5)$ & $12(50,0)$ \\
\hline & NR & $9(20,9)$ & $6(27,3)$ & $9(37,5)$ & - & $10(45,5)$ & $9(37,5)$ \\
\hline \multirow{3}{*}{ Elevação Laríngea } & Adeq & $28(65,1)$ & $12(54,6)$ & $10(41,7)$ & - & $10(45,5)$ & $10(41,7)$ \\
\hline & Alt & $1(2,3)$ & $3(13,6)$ & $4(16,6)$ & - & $2(9,0)$ & $5(20,8)$ \\
\hline & NR & $14(32,6)$ & $7(31,8)$ & $10(41,7)$ & - & $10(45,5)$ & $9(37,5)$ \\
\hline
\end{tabular}

Legenda: $\mathrm{FE} 1=$ faixa etária $1 ; \mathrm{FE} 2=$ faixa etária $2 ; \mathrm{FE} 3=$ faixa etária $3 ; \mathrm{ADEQ}=$ adequado; $\mathrm{ALT}=$ alterado; NR= não respondeu. Fonte: própria pesquisa 


\section{Discussão}

O presente estudo demonstrou que crianças com microcefalia decorrente da SCZ apresentaram importantes alterações na função alimentar, na deglutição e sucção. Baldrighi et al. (2015) ressaltaram que a influência recíproca entre as funções do sistema estomatognático e as estruturas e funcionamento do arcabouço craniofacial, favorece a interferência negativa dos distúrbios miofuncionais orofaciais sobre o desenvolvimento, o que pode ser observado nas crianças com microcefalia. Pesquisadores relatam que as crianças com microcefalia decorrente do ZIKV apresentam face aparentemente maior devido à desproporção craniofacial (Moore et al., 2017).

Um estudo recente ressalta que alterações encontradas na motricidade orofacial de crianças com microcefalia decorrem do comprometimento neurológico associado. Desta forma, a avaliação das estruturas e funções do sistema estomatognático é fundamental, visto que alterações nas funções de na sucção, deglutição, mastigação e respiração, podem trazer consequências negativas à saúde da criança, como a pneumonia aspirativa, desnutrição, desidratação, perda de peso (Faria et al., 2020).

No presente estudo foi possível observar alterações que caracterizaram a disfagia na alimentação com uso de mamadeira. Esses resultados demonstram difícil evolução do sistema estomatognático, o que leva a acreditar que há um comprometimento na execução dos atos motores realizados pelo complexo oromiofacial, com impacto negativo na funcionalidade da coordenação da sucção, deglutição e respiração (D’agostino, 2018; Faria et al., 2020).

Em relação à alimentação pastosa, houve aceitação em todas das crianças da FE2 e em 79,2\% da FE3. Quanto a ingesta de líquidos, verificou-se a ocorrência de engasgos, tosse, escape extraoral e resíduos pós-deglutição nas crianças da F2, entretanto, na FE 3 esses resultados foram inferiores, com exceção do engasgo e resíduo pós-deglutição, quando comparados com o período anterior. Os resultados de disfagia orofaríngea apresentados são compatíveis com o grau de lesão neurológica das crianças, bem como, as suas preferências alimentares, o que se pode concluir que não é possível determinar um padrão para o funcionamento do sistema estomatognático nessa população (Faria et al., 2020). Santos et al., (2019) avaliou 65 crianças com microcefalia e encontrou 52,3\% de disfagia em crianças entre 12-23 meses de idade com ingesta via oral pastosa. Neste período foram detectados sinais característicos de disfagia, tais como: engasgos, escape extraoral, tosse e resíduos após a deglutição na maioria da amostra. As evidências sugerem que as lesões cerebrais em crianças com microcefalia por ZIKV costumam acometer as áreas corticais e subcorticais, gânglios da base e tronco cerebral com possibilidade de disfagia (Furkim et al., 2003; Leal et al., 2017).

Também é importante considerar que a deglutição funcional do alimento pastoso apresentou melhora nos resultados de protrusão lingual, escape extraoral, tosse, sinais sugestivos de aspiração e ejeção adequada na FE3. Apesar das relações evolutivas encontradas nos resultados da coleta, é fato que a disfagia orofaríngea esteve presente em todo o período de avaliação, na maior parte das crianças. Os resultados encontrados neste trabalho evidenciaram maior comprometimento na fase oral da deglutição.

Ainda sobre os resultados acima se destaca o fato de que o alimento líquido trouxe mais dificuldade para as crianças quando comparada com a pastosa, com exceção na postura de língua, resíduos pós-deglutição e elevação laríngea, esta, apenas na FE3. Esse achado pode ser explicado como necessidade de maior controle motor oral, das respostas sensoriais das estruturas da cavidade oral e da coordenação da deglutição exigidas na consistência líquida (Vivone et al., 2007). Um estudo recente avaliou 116 crianças $(n=58$ com microcefalia, $n=58$ crianças sem microcefalia) e encontrou maior frequência de disfagia e anormalidades anatômicas e funcionais do sistema estomatognático em crianças com microcefalia relacionada ao Zika quando comparado aos controles (Oliveira et al., 2021).

O fato de não ter sido realizada avaliação mais específica da deglutição com exames objetivos e de imagem, pode ser considerada uma limitação deste estudo. Entretanto, utilizamos no nosso estudo uma ferramenta de avaliação clínica de baixo 
custo, sensível, fácil aplicabilidade, que não requer equipamento, evita a exposição ao bário e causa pouco desconforto no momento da avaliação. Assim, sugerimos estudos com exames objetivos da deglutição, a fim de fornecer informações sobre os processos disfágicos na população afetados pelo ZIKV. Além disso, o acompanhamento contínuo contribuirá para a compreensão de como as dificuldades de deglutição evoluem no decorrer do desenvolvimento da criança, com informações sobre estratégias terapêuticas de acompanhamento e cuidado.

Por fim, o trabalho fonoaudiológico deve considerar o desempenho nutricional da criança como um dos principais responsáveis pelo seu crescimento e desenvolvimento saudável veste a importância em suprir as necessidades metabólicas e energéticas do organismo. Sabe-se que as condições clínicas, neurológicas e maturacionais que o bebê se encontra ao nascer, junto ao estado de consciência, cognição, desenvolvimento motor, integridade e coordenação das estruturas e funções de sucção, deglutição e respiração são primordiais para a aceitação e alimentação oral adequada. Desta forma, destacamos a necessidade de uma assistência direcionada, integral e humanizada, a fim promover para a criança e a sua família uma melhor qualidade de vida, apesar de suas limitações.

\section{Conclusão}

A partir da análise dos dados sobre a função alimentar de crianças com microcefalia acometidas por Zika vírus, em três faixas etárias distintas foi possível concluir que ocorreram importantes alterações nas funções de sucção e deglutição. Estes achados indicam que esta população deve ser mantida em acompanhamento multidisciplinar.

\section{Referências}

Almeida, K. J., Martins, A. C. B., Gayoso e Almendra, I. C. C., De Meneses, G. M. S., De Oliveira Sampaio, T. D., Da Cruz Moura Campêlo, J., \& Bor-SengShu, E. (2019). Clinical aspects of congenital microcephaly syndrome by Zika virus in a rehabilitation center for patients with microcephaly. Revista Da Associacao Medica Brasileira, 65(10), 1249-1253. https://doi.org/10.1590/1806-9282.65.10.1249

Ashwal, S., Michelson, D., Plawner, L., \& Dobyns, W. B. (2009). Practice Parameter : Diagnostic assessment of the child with Report of the Quality Standards Subcommittee of the American Academy of Neurology and the Practice Committee of the Child Neurology Society. Neurology, 73, 887-897.

Baldrighi, S., César, C., Brito, A., Ferreira, G., Rodrigues, M., Nascimento, L., \& Santos, F. (2015). Perfil miofuncional orofacial de crianças atendidas no ambulatório odontopediátrico do Hospital Universitário de Aracaju/SE. Distúrbios Da Comunicação. ISSN 2176-2724, 27(1), 85-96.

Brasil, P., Jose P. Pereira, J., Gabaglia, C. R., Damasceno, L., Wakimoto, M., Nogueira, R. M. R., Sequeira, P. C. de, Siqueira, A. M., Carvalho, L. M. A. de, Cunha, D. C. da, Calvet, G. A., Neves, E. S., Moreira, M. E., Baião, A. E. R., Carvalho, P. R. N. de, Janzen, C., Valderramos, S. G., Cherry, J. D., Filippis, A. M. B. de, ... ABSTRACT. (2016). Zika Virus Infection in Pregnant Women in Rio de Janeiro - Preliminary Report. The New Engl and Journal of Medicine Original, 1-11. https://doi.org/10.1056/NEJMoa1602412

Carteaux, G., Maquart, M., Dessap, A. M., Bedet, A., Contou, D., Brugières, P., Fourati, S., Langavant, L. C. de, Broucker, T. de, Brun-Buisson, C., \& Leparc-Goffart, I. (2016). Zika Virus Associated with Meningoencephalitis. The New Engl and Journal of Medicine, 1-3. http://www.ncbi.nlm.nih.gov/pubmed/32293753

D’agostino, E. S. (2018). Universidade Federal Da Bahia Faculdade De Odontologia Programa De Pós-Graduação Em Odontologia E Saúde Alterações Orofaciais Em Crianças Com Microcefalia Associada À Exposição Fetal Ao Zika Vírus.

Faria, J. B. C., Feitosa, A. L. F., \& Canuto, M. S. B. (2020). Achados miofuncionais orofaciais em crianças com microcefalia. Distúrbios Da Comunicação, 32(3), 462-469. https://doi.org/10.23925/2176-2724.2020v32i3p462-469

Fujinaga, C. I., Scochi, C. G. S., Santos, C. B., Zamberlan, N. E., \& Leite, A. M. (2008). Validação do conteúdo de um instrumento para avaliação da prontidão do prematuro para início da alimentação oral. Revista Brasileira de Saúde Materno Infantil, 8(4), 391-399. https://doi.org/10.1590/s151938292008000400004

Furkim, A. M., Behlau, M. S., \& Weckx, L. L. M. (2003). Clinical and videofluoroscopic evaluation of deglutition in children with tetraparetic spastic cerebral palsy. Arquivos de Neuro-Psiquiatria, 61(3 A), 611-616. https://doi.org/10.1590/s0004-282x2003000400016

Gazeta, R. E., Bertozzi, A. P. A. P., Dezena, R. de C. de A. B., Silva, A. C. B., Fajardo, T. C. G., Catalan, D. T., Rizzo, M. de F. V., Moron, A. F., SorianoArandes, A., Clemente, N. S., Quintella, T., Ventura, D. F., Damico, F. M., de Matos França, V. de C. R., de Almeida, J. P. G., Zara, A. L. de S. A., Pires, L. C., Jundiaí, C. Z. V., \& Passos, S. D. (2021). Three-year clinical follow-up of children intrauterine exposed to zika virus. Viruses, 13(3). https://doi.org/10.3390/v13030523

Krauer, F., Riesen, M., Reveiz, L., Oladapo, O. T., Martínez-Vega, R., Porgo, T. V., Haefliger, A., Broutet, N. J., \& Low, N. (2017). Zika Virus Infection as a Cause of Congenital Brain Abnormalities and Guillain-Barré Syndrome: Systematic Review. PLoS Medicine, 14(1), 1-27. https://doi.org/10.1371/journal.pmed.1002203 
Leal, M. C., van der Linden, V., Bezerra, T. P., Valois, L., Borges, A., Antunes, M., Brandt, K., Moura, C., Rodrigues, L., \& Ximenes, R. (2017). Disfagia Hc. Emer, 23(8), 1253-1259.

Marinho, J. V. M. (2019). Aspectos estomatognáticos em crianças com microcefalia [CENTRO UNIVERSITÁRIO CESMAC]. https://ri.cesmac.edu.br/handle/tede/951

Marques, R. S., Vasconcelos, E. C., Andrade, R. M., \& Hora, I. A. D. A. (2018). Facial clinical findings in babies with microcephaly. Odonto, 25(49), 17-27. https://www.metodista.br/revistas/revistas-metodista/index.php/Odonto/article/view/8381/6385

Ministério da Saúde. (2015). Ministério da Saúde confirma relação entre zika e microcefalia. Ministério Da Saúde. https://portal.fiocruz.br/noticia/ministerioda-saude-confirma-relacao-entre-zika-e-microcefalia\#: :text=Em amostras de sangue e,inédita na pesquisa científica mundial

Mlakar, J., Korva, M., Tul, N., Popović, M., Poljšak-Prijatelj, M., Mraz, J., Kolenc, M., Resman Rus, K., Vesnaver Vipotnik, T., Fabjan Vodušek, V., Vizjak, A., Pižem, J., Petrovec, M., \& Avšič Županc, T. (2016). Zika Virus Associated with Microcephaly. New England Journal of Medicine, 374(10), 951-958. https://doi.org/10.1056/nejmoa1600651

Moore, C. A., Staples, J. E., Dobyns, W. B., Pessoa, A., Ventura, C. V., Da Fonseca, E. B., Ribeiro, E. M., Ventura, L. O., Neto, N. N., Arena, J. F., \& Rasmussen, S. A. (2017). Characterizing the pattern of anomalies in congenital zika syndrome for pediatric clinicians. JAMA Pediatrics, 171(3), 288-295. https://doi.org/10.1001/jamapediatrics.2016.3982

Oehler, E., Watrin, L., Larre, P., Leparc-Goffart, I., Lastãre, S., Valour, F., Baudouin, L., Mallet, H. P., Musso, D., \& Ghawche, F. (2014). Zika virus infection complicated by guillain-barré syndrome â€"case report, French Polynesia, December 2013. Eurosurveillance, 19(9), 7-9. https://doi.org/10.2807/15607917.es2014.19.9.20720

Oliveira, D. M. da S., Miranda-Filho, D. de B., Ximenes, R. A. de A., Montarroyos, U. R., Martelli, C. M. T., Brickley, E. B., Gouveia, M. de C. L., Ramos, R. C., Rocha, M. Â. W., Araujo, T. V. B. de, Eickmann, S. H., Rodrigues, L. C., Bernardes, J. P. de O. S., Pinto, M. H. T., Soares, K. P. N. D., Araújo, C. M. T. de, Militão-Albuquerque, M. de F. P., \& Santos, A. C. O. dos. (2021). Comparison of Oropharyngeal Dysphagia in Brazilian Children with Prenatal Exposure to Zika Virus, With and Without Microcephaly. Dysphagia, 36(4), 583-594. https://doi.org/10.1007/s00455-020-10173-4

Opitz, J. M., \& Holt, M. C. (1990). Microcephaly : general considerations and aids to nosology. J Craniofac Genet Dev Biol, 10(2), $175-204$.

Pereira, A.S, Shitsuka, D.L., Parreira, F.J., Shitsuka, R. Metodologia da Pesquisa Científica. UFSM.119p.

Reis, R. P. dos. (2015). Increased cases of microcephaly in Brazil. Revista Médica de Minas Gerais, 25(Supl 6), 88-89. https://doi.org/10.5935/22383182.20150101

Rosa, B. C. da S., Cesar, C. P. H. A. R., Paranhos, L. R., Guedes-Granzotti, R. B., Lewis, D. R., \& A. (2020). Speech-language disorders in children with congenital Zika virus syndrome: A systematic review. International Journal of Pediatric Otorhinolaryngology, 138(April), 1-12. https://doi.org/10.1016/j.ijporl.2020.110309

Santos, S. F. M. dos, Soares, F. V. M., De Abranches, A. D., Da Costa, A. C. C., Moreira, M. E. L., \& De Matos Fonseca, V. (2019). Infants with microcephaly due to ZIKA virus exposure: Nutritional status and food practices [Nutrition Journal]. In Nutrition Journal (Vol. 18, Issue 1). https://doi.org/10.1186/s12937-019-0429-3

Teixeira, G. A., Dantas, D. N. A., Carvalho, G. A. F. de L., da Silva, A. N., Lira, A. L. B. de C., \& Enders, B. C. (2020). Analysis of the concept of the zika virus congenital syndrome. Ciencia e Saude Coletiva, 25(2), 567-574. https://doi.org/10.1590/1413-81232020252.30002017

Vianna, C. I. O., \& Suzuki, H. S. (2011). Paralisia cerebral: análise dos padrões da deglutição antes e após intervenção fonoaudiológica. Revista CEFAC, 13(5), 790-800. https://doi.org/10.1590/s1516-18462011005000057

Vivone, G. P., Martins, M., Tavares, M., \& Bartolomeu, R. D. S. (2007). Deglutição em crianças com paralisia cerebral. 2 , $504-511$.

WHO. (2016). WHO Director-General summarizes the outcome of the Emergency Committee regarding clusters of microcephaly and Guillain- Barré syndrome. https://www.who.int/news/item/01-02-2016-who-director-general-summarizes-the-outcome-of-the-emergency-committee-regarding-clusters-ofmicrocephaly-and-guillain-barré-syndrome 